\title{
Performance of salt impregnated matrix materials for the long term thermochemical storage of low grade solar thermal energy
}

\author{
Robert J Sutton ${ }^{1}$, Eifion Jewell ${ }^{1}$, Jon Elvins ${ }^{1}$, Justin R. Searle ${ }^{1}$ \\ ${ }^{1}$ Swansea University \\ Swansea University \\ College of Engineering Bay Campus, Swansea, SA2 8EN, United Kingdom \\ robert.sutton@swansea.ac.uk; e.jewell@swansea.ac.uk; jonathon.elvins@ swansea.ac.uk; j.r.searle:Swansea.ac.uk
}

\section{Extended Abstract}

Transpired Solar Collectors (TSCs) are an effective technology for the capturing and distributing of solar thermal energy [1]. Due to the seasonal mismatch in solar thermal energy generation and building demand, there is requirement for the effective and economic long-term storage of excess solar thermal energy [2]. Thermochemical storage, via the hydration and dehydration of inorganic salts offer an appropriate solution compatible with the operational window of a TSC. Housing candidate salts within porous matrices reduces hysteresis and material degradation over dehydration cycles $[3,4]$.

Highly porous vermiculite was impregnated with $\mathrm{CaCl}_{2}, \mathrm{LiNO}_{3}$ and $\mathrm{MgSO}_{4}$ to form salt in matrices (SIMs) at a constant salt loading. The developed SIMs were characterised in terms of sorption capacity in a range of moisture laden environments, highlighting the superior sorption properties of $\mathrm{CaCl}_{2}$, thus its improved potential for thermal release. The sorption and desorption of the internally located salt was shown not to be hindered by the presence of the vermiculite matrix.

The discharge performance of SIMs in small volume applications is well understood and accepted to be very good [57], yet there is little work on higher scale applications, specifically building scale, which requires much higher material volumes and densities [7, 8]. A laboratory reactor was developed to investigate the performance of the SIMs at higher material packing densities. Reactor and exit temperatures were considerably lower than predicted, with a maximum peak lift of $10^{\circ} \mathrm{C}$ recorded at the reactor exit with the $\mathrm{V}-\mathrm{CaCl}_{2}$ SIM. Salt deliquescence at the reactor inlet, resulting from the hygroscopic nature of the $\mathrm{CaCl}_{2}$, led to poor salt utilization throughout the reactor. This poor salt utilization is identified as the primary source for the overall poor performance. The results indicate that the transit of moist air through column of packed material is limited to approximately $100 \mathrm{~mm}$ from the reactor inlet.

Conversely to $\mathrm{CaCl}_{2}$ and $\mathrm{LiNO}_{3}, \mathrm{MgSO}_{4}$ is considerably less hygroscopic, thus salt deliquescence was much less prominent with the $\mathrm{V}-\mathrm{MgSO}_{4} \mathrm{SIM}$. However, this reduction in moisture sorption resulted in poorer salt activation, and thus a lower thermal release throughout the reactor.

Variations to reactor design, orientation and operation were considered to reduce salt deliquescence and improve salt utilization. No improvements to material performance were observed from the considered variations [7, 8]. Improved moisture distribution within the reactor resulted in higher exit temperatures, with peak exit temperature lifts of $16^{\circ} \mathrm{C}$ recorded for the $\mathrm{V}-\mathrm{CaCl}_{2}$ SIM. However, low temperature lifts recorded within the reactor bulk highlight continuing poor salt activation

System performance of the laboratory scale reactor was seen to improve through the macro-scale combinations of the SIMs. SIMs were combined in both layered and blended scenarios [8,9], yielding a peak performance increase of up to $24 \%$ with the correct choice of mixing technique. Layering of $\mathrm{V}-\mathrm{CaCl}_{2}$ above $\mathrm{V}-\mathrm{LiNO}_{3}$ provided the most efficient thermal release, with an energy storage density of $0.2 \mathrm{GJ} / \mathrm{m}^{3}$, whilst the macro-blending of those SIMs surprisingly yielded the worst performance with a storage density of $0.01 \mathrm{GJ} / \mathrm{m}^{3}$, highlighting the importance of finding the correct mixing strategy.

All completed studies agree that material performance cannot simply be scaled for building scale applications. Reactor design and operation are vital to the successful implementation of building scale systems. As such, current work is looking at more intricate reactor design, aiming to match building scale energy densities with performance limiting steps, such as material depth, and salt loading, whilst independently conducting a thorough parametric study on operational variables. 


\section{References}

[1] M. Brower, Cool Energy. Chapter 3, MIT Press, 1992.

[2] J. Xu, R. Z. Wang and Y. Li, "A review of available technologies for seasonal thermal energy storage," Solar Energy, vol. 103, pp.610-638, 2014.

[3] B. Metter, H. Kerskes, H. Drück, "Concepts of long-term thermochemical energy storage for solar thermal applications - Selected examples," Energy Proceedia, vol. 30, pp. 321-330, 2012.

[4] S. P. Casey, D. Aydin, S. Riffat and J. Elvins. "Salt impregnated desiccant matrices for open thermochemical energy storage - Hygrothermal cyclic behaviour and energetic analysis by physical experimentation," Energy and Buildings, vol. 92, pp. 128-139, 2015.

[5] B. Michel, P. Neveu and N. Mazet, "Experimental investigation of an innovative thermochemical process for operating with a hydrate salt and moist air for thermal storage of solar energy: global performance," Applied Energy, vol. 129, pp. 177-186, 2014.

[6] B. Mette, H. Kerskes, H. Drücke and H. Müller-Steinghagen, "New highly efficient regeneration process for thermochemical energy storage," Applied Energy, vol. 109, pp. 352-359, 2013.

[7] R. J. Sutton, E. Jewell, J. Elvins, J. R. Searle and P. Jones, "Characterising the discharge cycle of $\mathrm{CaCl}_{2}$ and $\mathrm{LiNO}_{3}$ hydrated salts within a vermiculite composite scaffold for thermochemical storage," Energy and Buildings, vol. 162, pp. 109-120, 2018.

[8] R. J. Sutton, "Development of a thermochemical system for the long-term storage of low grade heat from renewable sources," EngD dissertation, College of Engineering, Swansea University, UK.

[9] R. Sutton, E. Jewell, J. Searle and J. Elvins. "Discharge performance of blended salt in matrix materials for low enthalpy thermochemical storage," Applied Thermal Engineering, 2018, vol. 145, pp. 483-493. 